\title{
Enhanced Thermal Performance and Impact Strength of UHMWPE/Recycled-PA6 Blends Synthesized via a Melting Extrusion Route
}

\author{
Xiuying Yang, ${ }^{1}$ Junye Cheng, ${ }^{2}$ Guangping Zheng, ${ }^{3}$ and Deqing Zhang ${ }^{1}$ \\ ${ }^{1}$ School of Materials Science and Engineering, Qiqihar University, Qiqihar 161006, China \\ ${ }^{2}$ Center of Super-Diamond and Advanced Films (COSDAF), Department of Physics and Materials Science, \\ City University of Hong Kong, Hong Kong \\ ${ }^{3}$ Department of Mechanical Engineering and Shenzhen Research Institute, Hong Kong Polytechnic University, \\ Hung Hom, Kowloon 999077, Hong Kong \\ Correspondence should be addressed to Guangping Zheng; g.zheng@polyu.edu.hk and Deqing Zhang; zhadqing@163.com
}

Received 11 January 2016; Accepted 10 April 2016

Academic Editor: Gianluca Cicala

Copyright (C) 2016 Xiuying Yang et al. This is an open access article distributed under the Creative Commons Attribution License, which permits unrestricted use, distribution, and reproduction in any medium, provided the original work is properly cited.

\begin{abstract}
The blends of ultra-high molecular weight polyethylene (UHMWPE) and recycled-polyamide 6 (R-PA6) were prepared via a melting extrusion route using high-density polyethylene-graft-maleic anhydride (HDPE-g-MAH) as the compatibilizer. The morphologies and distributions of the chemical components of the blends were characterized by scanning electron microscopy and synchrotron Fourier transform infrared microspectroscopy. The effects of R-PA6 content on the Vicat softening temperature (VST), heat distortion temperature (HDT), and impact strength of the blends were studied. Remarkably, in comparison with those of UHMWPE, the VST and HDT of UHMWPE/R-PA6 blends with 44 wt\% R-PA6 were increased to 165.1 and $98.4^{\circ} \mathrm{C}$, respectively, and the Charpy impact strength and Izod impact strength of the blends were enhanced to 33.9 and $16.2 \mathrm{~kJ} / \mathrm{m}^{2}$, respectively. In addition, it was found that the blending system containing $44 \mathrm{wt} \%$ R-PA6 and $48 \mathrm{wt} \%$ UHMWPE exhibited the best compatibility when it was prepared using $8 \mathrm{wt} \%$ HDPE-g-MAH. The distribution of the phases of UHMWPE and R-PA6 was uniform, and no obvious phase separation was observed in the blends.
\end{abstract}

\section{Introduction}

Ultra-high molecular weight polyethylene (UHMWPE) has a relative molecular weight ranging from 1.5 to 8 million, a dense crystal structure, and excellent chemical inertia. As a consequence, the strength of UHMWPE is not much affected by strong acids and base solutions as well as organic solvents. Besides its chemical stability, UHMWPE possesses the properties of low water absorption, excellent resistances to low temperature, aging, wear, and fatigue, and outstanding toughness for the resistance of impact and cutting. The impact strength of UHMWPE can reach $>1070 \mathrm{~J} / \mathrm{m}$ of the notch and the wear resistance was reported to be $\sim 0.25 \%$ of wear rate per cycle. Therefore, UHMWPE has been widely used in various fields such as textile, paper, machinery, and mining [1-4]. In particular, because of their low friction coefficient, high wear, and corrosion resistances, UHMWPElined pipes are widely used in oilfields to extend the wax cleaning cycle of oilfield and reduce the swabbing loads as well as the energy consumption during the manufacturing processes of oilfields. Furthermore, UHMWPE is also utilized to repair the old oil pipes to extend their service life time and reduce the production cost of the oilfield [5]. In the oilfields, the actual operating temperature of lined pipes can reach $125^{\circ} \mathrm{C}$, whereas the Vicat softening temperature (VST) of the UHMWPE-lined pipes is only $127^{\circ} \mathrm{C}$ due to the effects of molding process on VST (the VST of UHMWPE resin is $131^{\circ} \mathrm{C}$ ). The low VST reduces the ability of UHMWPE-lined pipes to withstand external loads and increases their damage rate. It is thus an urgent need to increase the softening temperature of UHMWPE-lined pipes of oil wells. 
Polyamide 6 (PA6) has been widely used in the fields of electricity, machinery, and automobile because of its excellent mechanical properties, abrasion resistance, and workability [6-8]. In spite of high strength, wear and heat resistance, and ease of fabrication and processing for PA6, however, its impact strength, dimensional stability, and barrier properties to moisture are very poor, which limits its application in many fields. The above shortcomings of PA6 can be compensated by blending it with UHMWPE, which has high strength and modulus, high barrier properties to moisture, good wear resistance, and excellent impact strength at low temperature previously mentioned. Unfortunately, UHMWPE is immiscible with PA6. By simple blending of these polymers, we obtained a coarse-phase structure with low interfacial adhesion, leading to poor mechanical properties of the blend. Therefore, it is necessary to incorporate into the blended system a compatibilizer which forms bonds at the interface and imparts to the blend good mechanical properties. In the previous work on the blending modification of UHMWPE and PA6, the major goals were to improve the tensile and impact performances of PA6 by adding a small amount of UHMWPE, and to investigate the effects of compatibilizer [9]. Using HDPE-g-MAH as a compatibilizer for the blends of PA6/UHMWPE (80/20), it was found that the dimensions of UHMWPE domains in the PA6 matrix decreased dramatically as compared with those of the uncompatibilized blending systems [10]. The tensile strength and Izod impact strength of PA6/UHMWPE/HDPE-g-MAH (80/20/20) were about 1.5 1.6 times as high as those of PA6/UHMWPE $(80 / 20)$ [10]. The UHMWPE-g-acrylic acid was also used as a compatibilizer to prepare the PA6/UHMWPE blends. Investigations on the mechanical property, impact property, crystallization behavior, and frictional property of PA6/UHMWPE suggested that these properties depended mostly on the interfacial structures and the compatibility between UHMWPE and polyamide [11].

In this study, we fully take advantage of the high VST of recycled-PA6 (R-PA6) which can reach up to $210^{\circ} \mathrm{C}$ and prepare the UHMWPE/R-PA6 blends using HDPE-g-MAH as the compatibilizer. The effects of the blending compositions on the VST, heat distortion temperature (HDT), impact resistance, and blending morphologies are investigated. This study could lay a solid foundation for the industrial applications of UHMWPE-lined pipes in oilfield with low cost and high VST.

\section{Experimental}

2.1. Materials. UHMWPE (M-III) of a weight-average molecular weight of 3.5 million was purchased from Beijing Chemical Agent Second Factory. R-PA6 with a relative viscosity larger than 2.5 and HDPE-g-MAH with a grafting ratio of $0.8 \mathrm{wt} \%$ were prepared in our lab based on reported methods $[10,12]$.

2.2. Preparation Process. R-PA6 was first dried at $80^{\circ} \mathrm{C}$ for $12 \mathrm{~h}$ in vacuum. Then HDPE-g-MAH, UHMWPE, and dried RPA6 were mixed in certain proportion. The blends were prepared by reactive blending of the components in a homemade

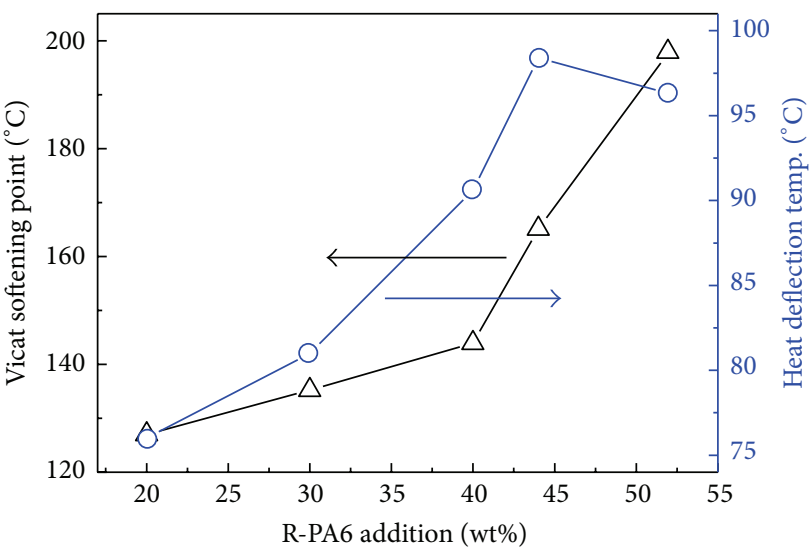

FIGURE 1: The effect of R-PA6 content on the thermal performance of UHMWPE/R-PA6/HDPE-g-MAH.

twin-screw extruder $(\phi=30 \mathrm{~mm}$ and $L / D=44)$ at a constant speed of $160 \mathrm{r} / \mathrm{min}$. The processing temperature was at about $235-250^{\circ} \mathrm{C}$. In the next step, the extruded material was granulated and dried. Subsequently the obtained material was molded into specimens using an injection molding machine. Finally the specimens were annealed at $80^{\circ} \mathrm{C}$ for $3 \mathrm{~h}$ to reduce the internal stresses.

2.3. Characterization. The Charpy impact strength, Izod impact strength, VST, and HDT were measured according to the ISO 179-1: 2000, ISO 180: 2000, ISO 306: 1994, and ISO 75-1: 2003 protocols, respectively. Thermal analyses were performed by differential scanning calorimetry (DSC, Netzsch $204 \mathrm{~F} 1$, Germany) in air at a heating rate of $10^{\circ} \mathrm{C} / \mathrm{min}$. A scanning electron microscope (SEM, HITACHI S-4300, HITACHI, Japan) was used to observe the morphologies of the blends. Before observation, the examined sections were coated with gold in a vacuum. Synchrotron FTIR microspectroscopy and mapping technology (FTIR/NIR Spectrometer Frontier and FTIR Microscope Spotlight 400, PE, USA) were used to characterize the compositions and distributions of the blending materials.

\section{Result and Discussion}

It is known that the VST and HDT of UHMWPE are $127^{\circ} \mathrm{C}$ and $95^{\circ} \mathrm{C}$, respectively, whereas the VST and HDT of R-PA6 are $213^{\circ} \mathrm{C}$ and $177^{\circ} \mathrm{C}$, respectively [13,14]. Figure 1 shows the effects of R-PA6 additions on the VST and HDT of UHMWPE/PA blends prepared by using $8 \mathrm{wt} \%$ HDPE-gMAH compatibilizer. The VST and HDT increase gradually with increasing content of R-PA6. When the contents of RPA6 are $44 \mathrm{wt} \%$ and $52 \mathrm{wt} \%$, the VST of the UHMWPE/PA blends reach $165.1^{\circ} \mathrm{C}$ and $197.9^{\circ} \mathrm{C}$, respectively, and the HDT are as high as $98.4^{\circ} \mathrm{C}$ and $96.3^{\circ} \mathrm{C}$, respectively. The results demonstrate that the addition of R-PA6 significantly improves the thermal performance of UHMWPE/PA.

Figure 2 shows the effects of R-PA6 addition on the impact strength of UHMWPE/R-PA6/HDPE-g-MAH. As the R-PA6 content increases, both the Charpy impact strength 


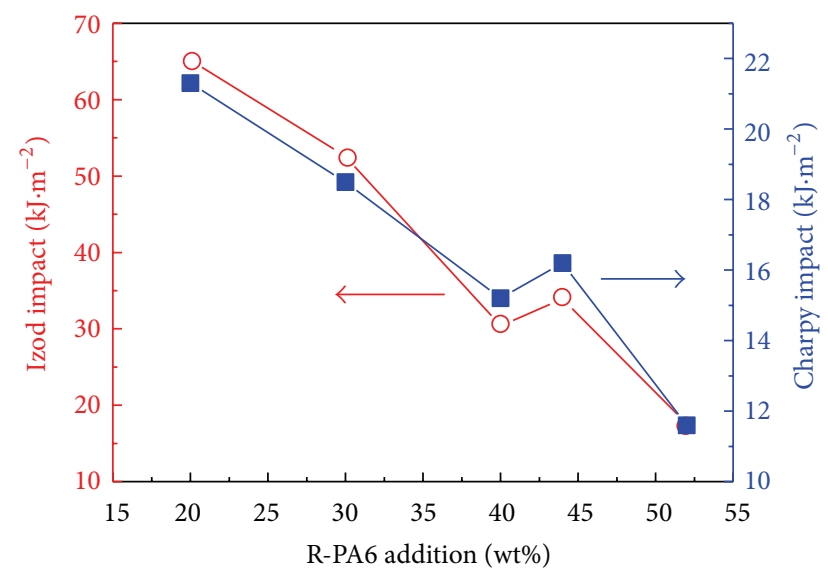

FIgURE 2: The effect of R-PA6 content on the impact strength of UHMWPE/R-PA6/HDPE-g-MAH.

and Izod impact strength of UHMWPE/R-PA6/HDPE-gMAH tend to decrease, which are mainly attributed to the low impact strength of the R-PA6 component [15]. The impact performance is also associated with the effects of HDPE-g$\mathrm{MAH}$ on the compatibility and the distribution of blending components [16]. When the HDPE-g-MAH is dispersed on the interface between UHMWPE and R-PA6, the MAH segments of HDPE-g-MAH could react with the terminal amines or carboxyl groups of R-PA6, resulting in the reduced interfacial tension, the improved interfacial wetting, and the enhanced interfacial bonding strength for more convenient load transfer and better dispersion of the components. As a consequence, the impact strength of UHMWPE/RPA6 can be improved. However, the HDPE-g-MAH only enhances the compatibility between R-PA6 and UHMWPE with appropriate contents and the excessive or too less RPA6 content would reduce the compatibility, resulting in the reduced impact strength of UHMWPE/R-PA6. As shown in Figure 2, when the content of R-PA6 is $44 \mathrm{wt} \%$, the impact strength of UHMWPE/R-PA6 reaches a local maximum. For example, the Charpy impact strength and Izod impact strength of UHMWPE/R-PA6 with 44 wt\% R-PA6 are 33.9 and $16.2 \mathrm{~kJ} / \mathrm{m}^{2}$, respectively, which could meet the impact strength requirement for oil exploitation equipment.

Figure 3 shows the DSC curves of UHMWPE/RPA6/HDPE-g-MAH blending materials with different chemical compositions. As shown in Figure 3, distinct melting and decomposition peaks in the DSC curves for the blends can be observed at $0 \sim 600^{\circ} \mathrm{C}$, and the peak temperatures are almost independent of the R-PA6 content. These observations suggest that UHMWPE and R-PA6 are thermodynamically incompatible. Hence, the blending process seems to have no obvious effects on their crystal morphologies, melting points, and thermal decompositions. In addition, it is noted that the melting points of neat R-PA6 and UHMWPE are both higher than other UHMWPE/R-PA6/HDPE-g-MAH blends. This may be attributed to the lower crystallinity for blending materials after melt blending of different components.

Figure 4 shows the SEM images of the fracture surfaces of the UHMWPE/R-PA6/HDPE-g-MAH blending materials

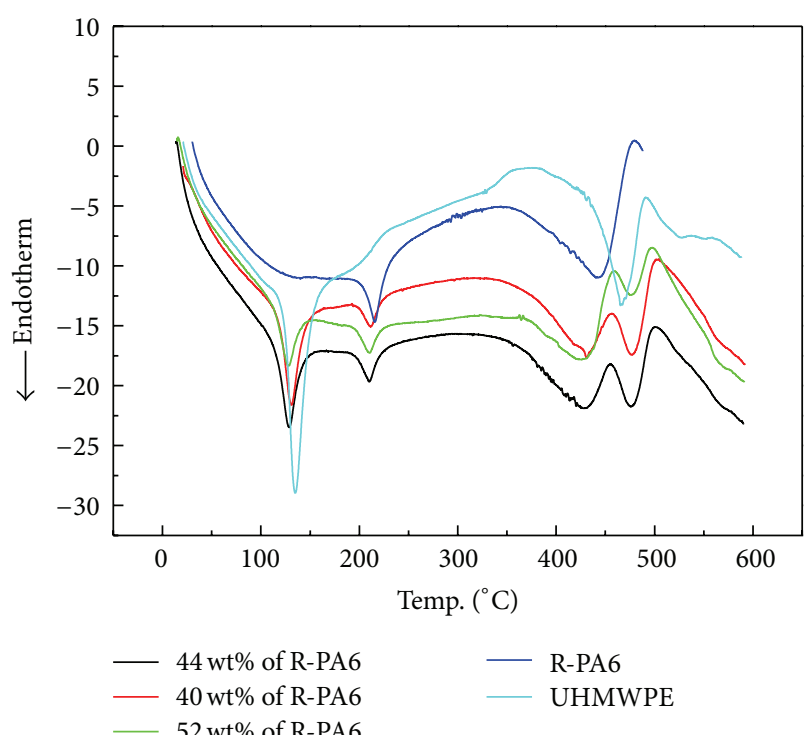

FIGURE 3: DSC curves of UHMWPE/R-PA6/HDPE-g-MAH with different amounts of R-PA6 and neat UHMWPE.

with different chemical compositions. The two components, UHMWPE and R-PA6, can not be distinguished in these images. When the content of R-PA6 is $40 \mathrm{wt} \%$, large cracks and wiredrawing-like HDPE-g-MAH are found on the fracture surface of the UHMWPE/R-PA6/HDPE-g-MAH blending materials. When the content of R-PA6 is $44 \mathrm{wt} \%$, instead, less cracks and dramatically reduced wiredrawinglike HDPE-g-MAH are observed on the fracture surface which is relatively uniform and smooth compared to that of the blend with a R-PA6 content of $40 \mathrm{wt} \%$. As a contrast, Figure 4(c) shows the SEM image of the fracture surfaces of the UHMWPE/R-PA6 blending materials without compatibilizer. From this image, it is found that there is obvious separation of the two phases and R-PA6 takes on sphere-like shape. These results indicate that when the RPA6 content is $44 \mathrm{wt} \%$, with $8 \mathrm{wt} \%$ HDPE-g-MAH as the compatibilizer, the compatibility between UHMWPE and RPA6 is the best. Because the dispersion of HDPE-g-MAH molecules at the interface between the two incompatible phases could reduce the interfacial tension, improve the viscosity between phases, and promote the integration of these two phases, therefore the HDPE-g-MAH improves the compatibility between UHMWPE and R-PA6 and their phase interface becomes indistinct and the number of cracks can be decreased on the fracture surface.

Synchrotron FTIR microspectroscopy and mapping technology have been employed to better characterize the phase separation of UHMWPE and R-PA6 in the blends. As shown in Figure 6, the peak at $1637.8 \mathrm{~cm}^{-1}$ is attributed to the typical absorption peak of the carbonyl group in the amide, indicating that the chemical component at point $\mathrm{A}$ in Figure 5 could be R-PA6 [17]. Single-peak comparison mode for the peak at $1637.8 \mathrm{~cm}^{-1}$ is shown in Figure 7 where the upward convex portion results from the peak at $1637.8 \mathrm{~cm}^{-1}$, that is, the R-PA6 component. As shown in Figure 7, with $8 \mathrm{wt} \%$ 


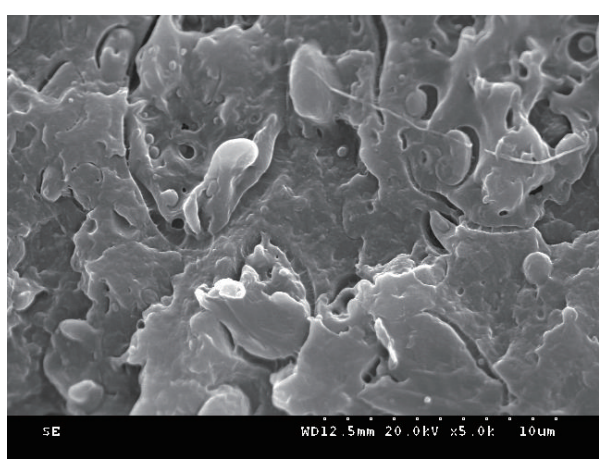

(a)

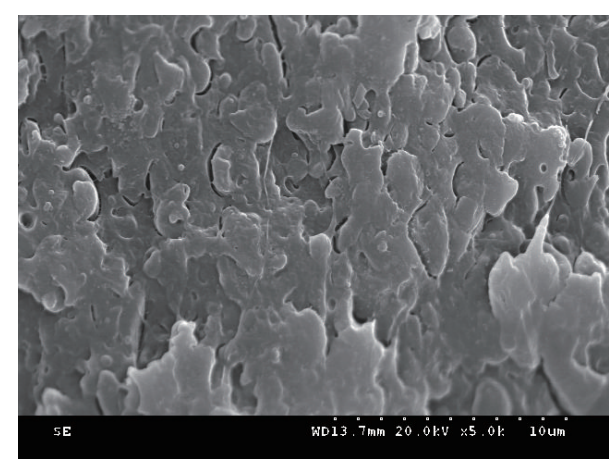

(b)

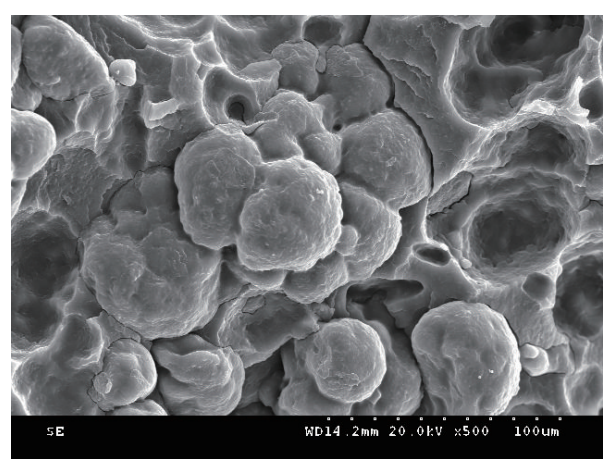

(c)

FIgURE 4: SEM images of UHMWPE/R-PA6/HDPE-g-MAH blending material with different R-PA6 compositions: (a) 40 wt\% and (b) $44 \mathrm{wt} \%$; (c) SEM image of UHMWPE/R-PA6 blending material.

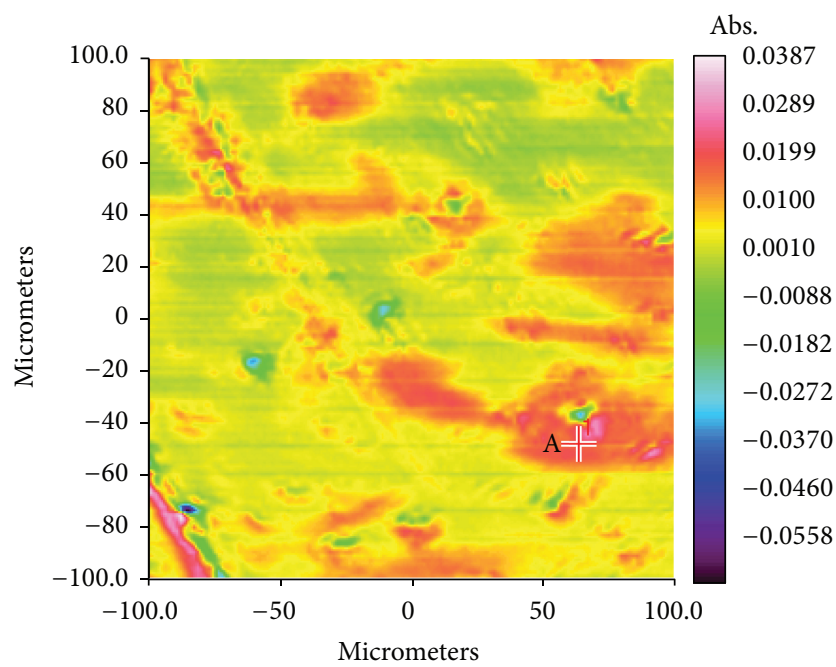

FIGURE 5: Intensity distribution map of UHMWPE/R-PA6/HDPEg-MAH sample with 40 wt\% R-PA6.

HDPE-g-MAH as the compatibilizer, the distribution of R-PA6 in UHMWPE/R-PA6 with $44 \mathrm{wt} \%$ R-PA6 is more uniform than that in UHMWPE/R-PA6 with 40 wt\% R-PA6. The result is in good agreement with the observation that the UHMWPE/R-PA6 with 44 wt\% R-PA6 has a better impact strength, as shown in Figure 2.

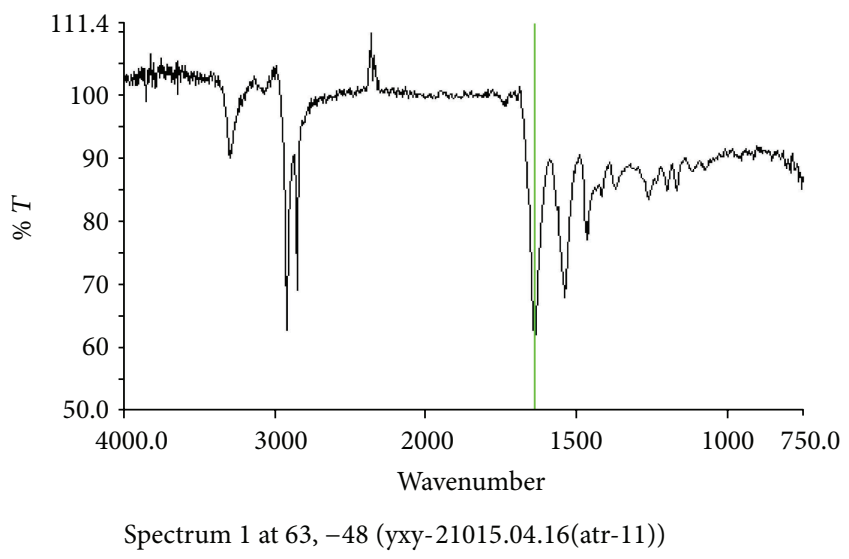

FIgURE 6: FTIR spectrum at point $\mathrm{A}$ in Figure 5. The peak at $1637.8 \mathrm{~cm}^{-1}$ is indicated.

\section{Conclusion}

The VST and HDT of the UHMWPE/R-PA6/HDPE-g-MAH blends containing $8 \mathrm{wt} \%$ of HDPE-g-MAH compatibilizer and $44 \mathrm{wt} \%$ R-PA6 are as high as $165.1^{\circ} \mathrm{C}$ and $98.4^{\circ} \mathrm{C}$, respectively, and the Charpy strength and Izod impact strength are 33.9 and $16.2 \mathrm{~kJ} / \mathrm{m}^{2}$, respectively. The results of DSC, SEM, and synchrotron FTIR microspectroscopy and mapping technology demonstrate that the UHMWPE and RPA6 are thermodynamically incompatible. Remarkably, the 


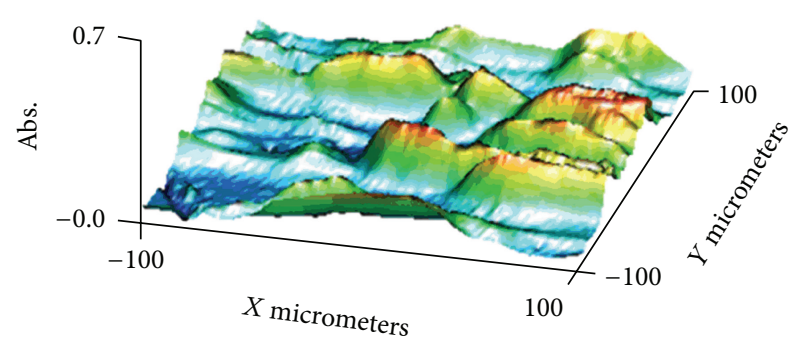

(a)

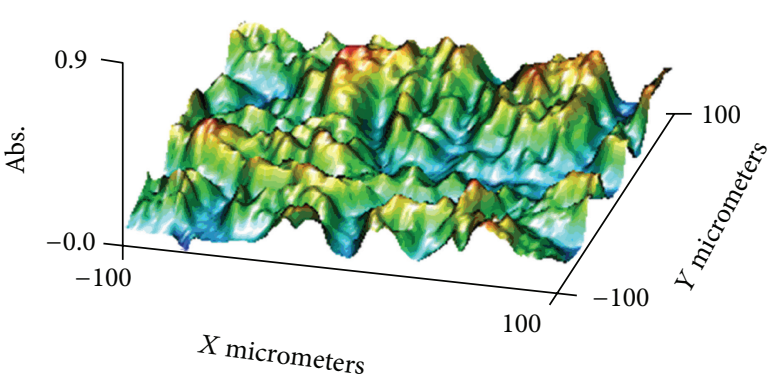

(b)

FIGURE 7: Intensity distribution 3D-maps of synchrotron FTIR microspectroscopy at $1637.8 \mathrm{~cm}^{-1}$ and mapping for the fracture surface of UHMWPE/R-PA6/HDPE-g-MAH blends with different R-PA6 compositions: (a) $40 \mathrm{wt} \%$ and (b) $44 \mathrm{wt} \%$.

addition of R-PA6 is found to effectively increase the VST and HDT of UHMWPE material systems and reduce the cost of materials for UHMWPE-lined pipes.

\section{Competing Interests}

The authors declare that they have no competing interests.

\section{Acknowledgments}

This work was supported by the National Natural Science Foundation of China (51272110), the Natural Science Foundation of Heilongjiang Province (E201101), the Scientific Research Project of Education Bureau of Heilongjiang Province (12521592), the Science Research Project of Key Laboratory of Fine Chemicals of College of Heilongjiang Province of China (JX201203), and the Science and Technology Innovation Commission of Shenzhen (no. JCYJ2013041152508657).

\section{References}

[1] P. Smith and P. J. Lemstra, "Ultra-high-strength polyethylene filaments by solution spinning/drawing," Journal of Materials Science, vol. 15, no. 2, pp. 505-514, 1980.

[2] D. M. Bigg, M. M. Epstein, R. J. Fiorentino, and E. G. Smith, "Continuous extrusion of high-modulus semicrystalline polymers," Journal of Applied Polymer Science, vol. 26, no. 2, pp. 395409, 1981.

[3] P. Campbell, S. Ma, B. Yeom, H. McKellop, T. P. Schmalzried, and H. C. Amstutz, "Isolation of predominantly submicronsized UHMWPE wear particles from periprosthetic tissues," Journal of Biomedical Materials Research, vol. 29, no. 1, pp. 127131, 1995.

[4] H.-G. Willert, H. Bertram, and G. Hans Buchhorn, "Osteolysis in alloarthroplasty of the hip: the role of ultra-high molecular weight polyethylene wear particles," Clinical Orthopaedics and Related Research, no. 258, pp. 95-107, 1990.

[5] Y. Lei, J. L. Guo, and X. D. Peng, "Molding technology of ultra high molecular weight polyethylene pipe and its application in oil and gas storage and transportation," Petroleum Engineering Construction, vol. 31, pp. 1-3, 2005.

[6] W. S. Chow, Z. A. M. Ishak, J. Karger-Kocsis, A. A. Apostolov, and U. S. Ishiaku, "Compatibilizing effect of maleated polypropylene on the mechanical properties and morphology of injection molded polyamide 6/polypropylene/organoclay nanocomposites," Polymer, vol. 44, no. 24, pp. 7427-7440, 2003.

[7] J. Roeder, R. V. B. Oliveira, M. C. Gonçalves, V. Soldi, and A. T. N. Pires, "Polypropylene/polyamide- 6 blends: influence of compatibilizing agent on interface domains," Polymer Testing, vol. 21, no. 7, pp. 815-821, 2002.

[8] C. Damm, H. Münstedt, and A. Rösch, "The antimicrobial efficacy of polyamide 6/silver-nano- and microcomposites," Materials Chemistry and Physics, vol. 108, no. 1, pp. 61-66, 2008.

[9] H.-G. Wang, L.-Q. Jian, B.-L. Pan, J.-Y. Zhang, and S.-R. Yang, "Mechanical and tribological behaviors of polyamide 66/ultra high molecular weight polyethylene blends," Polymer Engineering and Science, vol. 47, no. 5, pp. 738-744, 2007.

[10] Z. H. Yao, Z. H. Yin, G. E. Sun et al., "Morphology, thermal behavior, and mechanical properties of PA6/UHMWPE blends with HDPE- $g$-MAH as a compatibilizing agent," Journal of Applied Polymer Science, vol. 75, no. 2, pp. 232-238, 2000.

[11] Z. Denchev and N. Dencheva, "Manufacturing and properties of aramid reinforced composites," in Synthetic Polymer-Polymer Composites, chapter 8, pp. 251-280, Carl Hanser Verlag GmbH \& Co, 2012.

[12] Y. Gong and G. Yang, "Single polymer composites by partially melting recycled polyamide 6 fibers: preparation and characterization," Journal of Applied Polymer Science, vol. 118, no. 6, pp. 3357-3363, 2010.

[13] I. Kotter and W. Grellmann, Polymer Solids and Polymer MeltsMechanical and Thermomechanical Properties of Polymers, vol. 6A3 of Landolt-Börnstein-Group VIII Advanced Materials and Technologies, Springer, 2014.

[14] D. Ghidoni, E. Bencini, and R. Nocci, "Compatibilizing PPE and PA6 with nitro-phthalimide derivatives," Journal of Materials Science, vol. 31, no. 1, pp. 95-101, 1996.

[15] S. C. Tjong, S. A. Xu, and Y. W. Mai, "Impact fracture toughness of short glass fiber-reinforced polyamide 6,6 hybrid composites containing elastomer particles using essential work of fracture concept," Materials Science and Engineering A, vol. 347, no. 1-2, pp. 338-345, 2003.

[16] M. Pracella, L. Rolla, D. Chionna, and A. Galeski, "Compatibilization and properties of poly(ethylene terephthalate)/ polyethylene blends based on recycled materials," Macromolecular Chemistry and Physics, vol. 203, no. 10-11, pp. 1473-1485, 2002.

[17] O. De Giacomo, A. Cesàro, and L. Quaroni, "Synchrotron based FTIR spectromicroscopy of biopolymer blends undergoing phase separation," Food Biophysics, vol. 3, no. 1, pp. 77-86, 2008. 

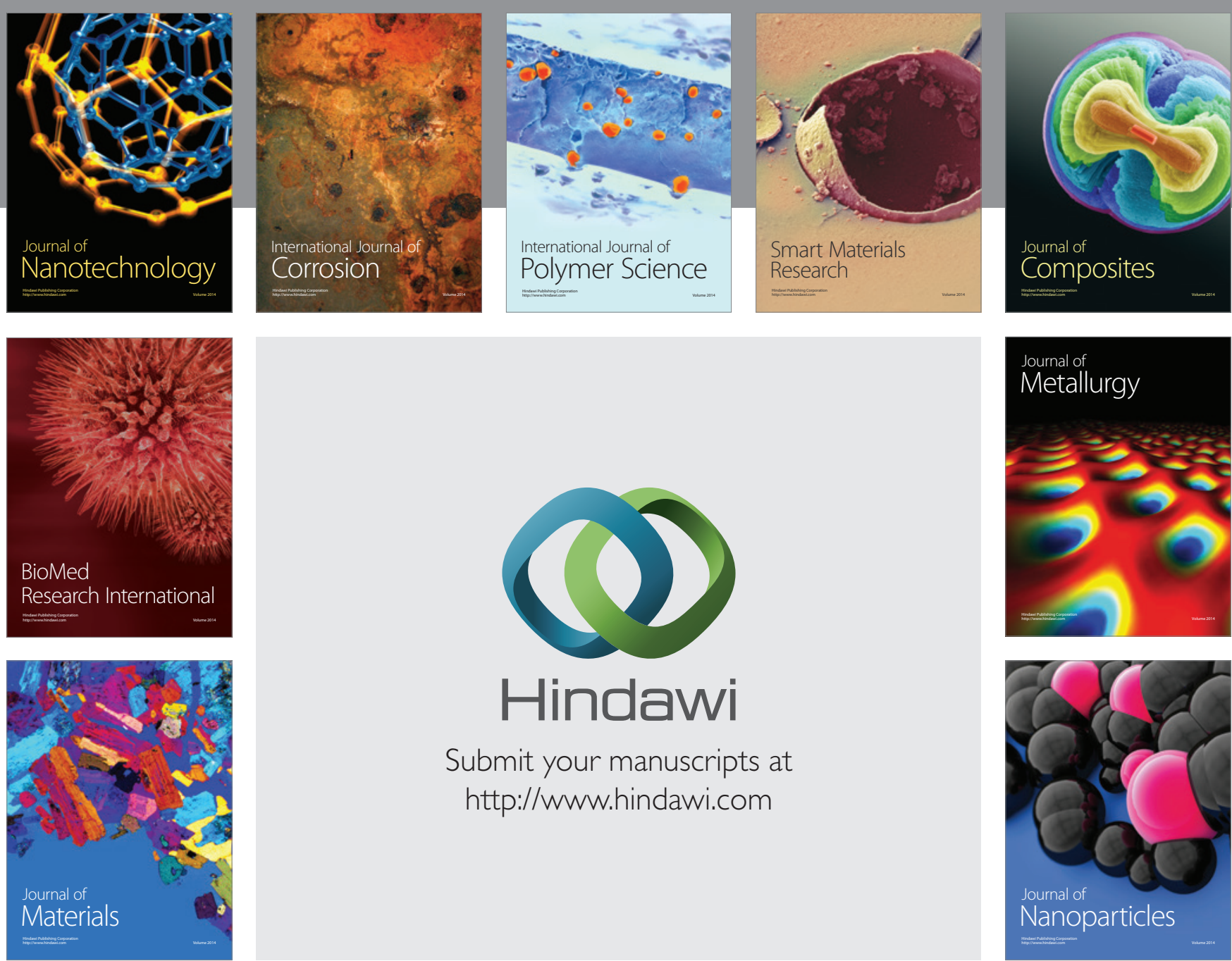

\section{Hindawi}

Submit your manuscripts at

http://www.hindawi.com



Materials Science and Engineering
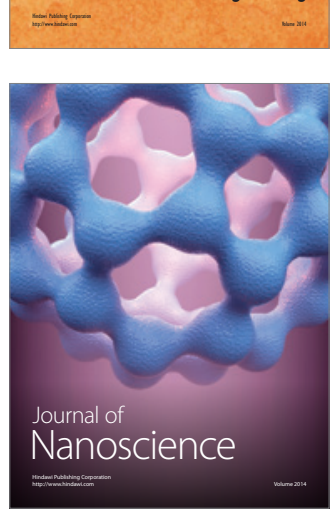
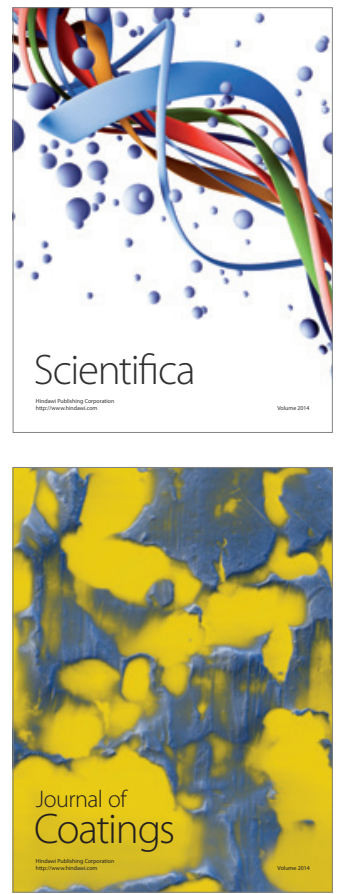
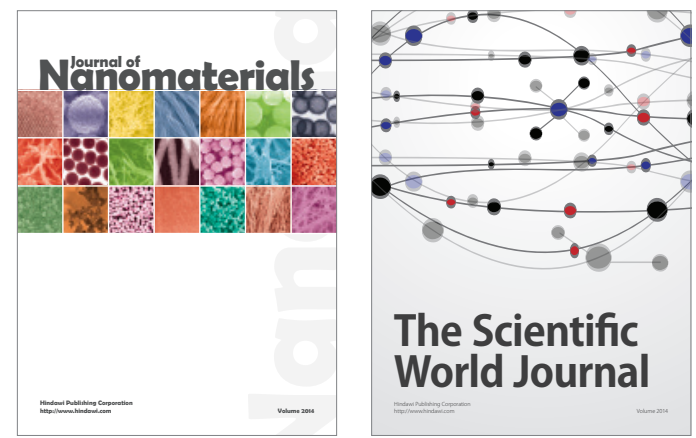

The Scientific World Journal
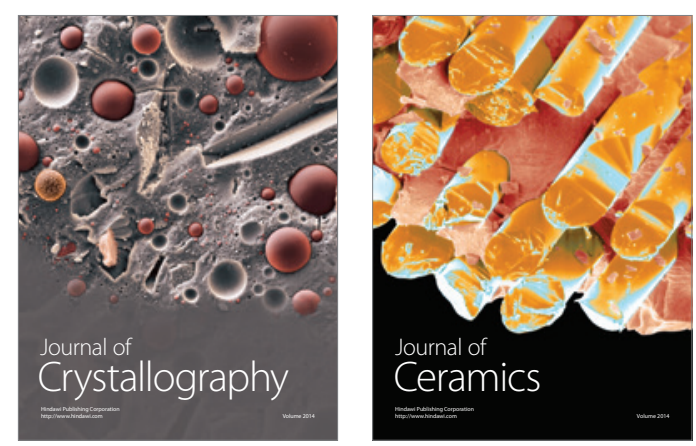
